\title{
Monitoring precipitation kinetics in heat treatable aluminium alloys using in-situ resistivity in Gleeble thermomechanical simulator
}

\author{
Nicolas Chobaut ${ }^{1, a^{*}}$, Denis Carron ${ }^{2, b}$ and Jean-Marie Drezet ${ }^{1, c}$ \\ ${ }^{1}$ Ecole Polytechnique Fédérale de Lausanne, Laboratoire de Simulation des Matériaux, station 12, \\ $\mathrm{CH}-1015$ LAUSANNE, Switzerland \\ ${ }^{2}$ Univ Bretagne Sud, LIMATB, EA 4250, Rue de St Maudé, F-56100, LORIENT, France \\ anicolas.chobaut@epfl.ch, ${ }^{\mathrm{b}}$ denis.carron@univ-ubs.fr, ${ }^{\mathrm{c}}$ jean-marie.drezet@epfl.ch \\ ${ }^{*}$ corresponding author
}

Keywords: Aluminium alloys, precipitation, resistivity, Gleeble machine.

\begin{abstract}
A conventional way to determine precipitation kinetics in heat treatable aluminium alloys is to monitor the associated solute loss by in-situ resistivity. A Gleeble machine is used to perform so called isothermal quenching (IQ) resistivity measurements. IQ consists in quenching the alloy down to a given temperature and holding it at this temperature. The results are validated against measurements performed with a classical four-points method using continuous current on the same alloy.
\end{abstract}

\section{Introduction}

In the processing route of heat-treatable aluminium alloys (AA), a determining step for the final properties is quenching from the solution heat treatment (SHT) temperature. From a metallurgical point of view, the ideal quench must be fast enough to avoid the formation of precipitates during quenching i.e. to obtain a supersaturated solid solution (SS). However, fast quenching cannot be achieved in the centre of thick components, where the quenching rate can be more than one order of magnitude lower than at the surface. This results in coarse precipitation which is detrimental to the final yield strength since it decreases the hardening potential by pumping solute elements during quench.

A number of methods (Jominy test, resistivity, thermoelectric power) have been developed to measure indirectly the loss of solute during quenching $[1,2]$. The traditional way to monitor solute loss is to measure the drop of hardness in T6-state after an isothermal holding at high temperature. Such measurements being time consuming, in-situ resistivity has proven to be a useful technique to characterise precipitation kinetics in AA $[3,4]$. Resistivity is monitored to determine the solute loss associated with the formation of precipitates according to Mathiessen's rule, stating that the effect of dissolved alloying elements on the electrical resistivity of a metallic alloy is linear and additive [5].

Archambault and Godard used a home-made quenching resistivimeter to characterise precipitation kinetics in $\mathrm{Al}-\mathrm{Zn}-\mathrm{Cu}-\mathrm{Mg}$ based 7010 alloy [4]. After validating in-situ resistivity measurements upon cooling at constant cooling rates against differential scanning calorimetry measurements, they performed isothermal quenching (IQ) measurements at different temperatures. The results were used to calibrate a precipitation model and to draw the Time-TemperatureTransformation (TTT) diagram of AA7010. Such data is useful to assess the quench sensitivity of heat treatable aluminium alloys and to design adequate heat treatments. Yet IQ resistivity has remained a minor technique in the last decade, probably because precise control of isothermal quenching cycle is difficult in conventional resistivimeters.

In the present work, we demonstrate the ability of the commercially available Gleeble machine to characterise precipitation kinetics by isothermal quenching resistivity measurements. AA7010 was used to compare our method using alternative current in the Gleeble machine with the classical four- 
points method using continuous current in the quenching resistivimeter used by Archambault and Godard and described in [3].

\section{Experimental procedure}

Material. Specimens were cut at quarter thickness of a $110 \mathrm{~mm}$ thick AA7010 plate provided by Constellium. All specimens where solutionised in the Gleeble machine for $15 \mathrm{~min}$ at $475^{\circ} \mathrm{C}$ and then quenched at constant cooling rate of $20^{\circ} \mathrm{C} / \mathrm{s}$ to the desired temperature.

Resistivity measurements. The Gleeble machine, originally dedicated to thermomechanical testing, was selected to carry out the isothermal quenching resistivity measurements because of its reliability in controlling temperature. The specimen is heated via Joule effect using alternative current and cooled by water-cooled grips. Specimen temperature is monitored by three thermocouples fixed to the specimen's surface. A closed-loop feedback control system enables precise control of the heat input based on the temperature. Whenever a current is sent through the sample to heat it up, a potential difference is measured between two cooper wires fixed to the specimen's surface at \pm 5 $\mathrm{mm}$ from the position of the central thermocouple TC1. The electrical resistance is then calculated by the Gleeble system and recorded at $100 \mathrm{~Hz}$ to capture the very beginning of precipitation.

A compromise was found between high cooling rates (to avoid precipitation during cooling from the SHT temperature to the isothermals) and low axial thermal gradient in the operating area, i.e. between the two copper wires. This was achieved by using copper grips and an optimised specimen geometry. Cylindrical (6 mm diameter) specimen geometries (Fig. 1) with $3 \mathrm{~mm}$ reduced diameter on each side of the operating area as proposed by Samuel and Viswanathan [6] were designed.
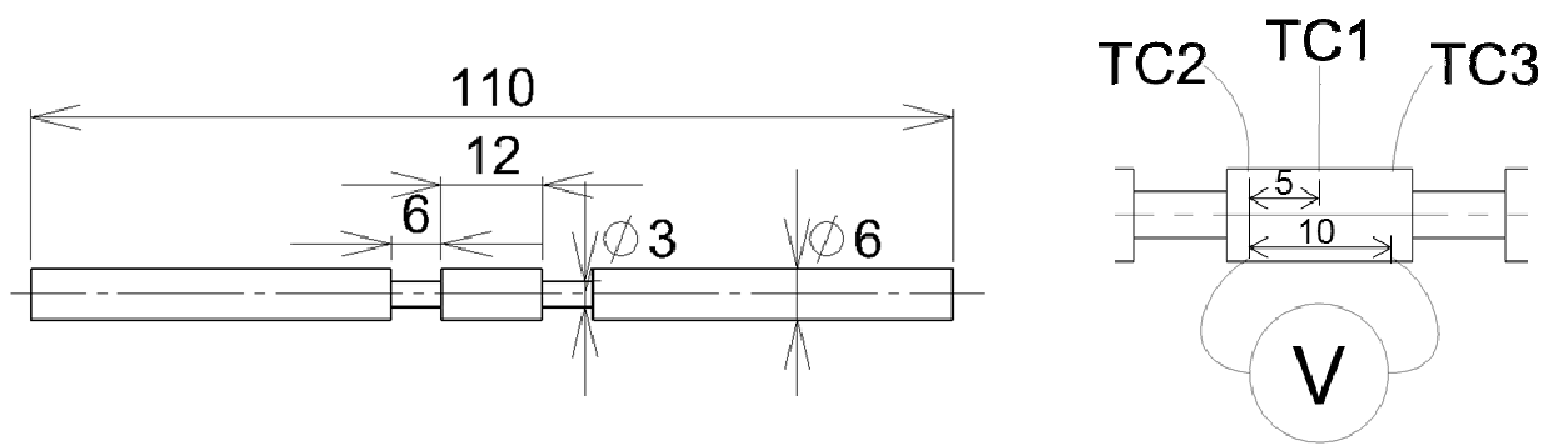

Figure 1: Specimen geometry used for resistivity measurements with dimensions in millimeters (left) and position of thermocouples (right).

The combination of cooper grips and the optimised geometry resulted in a maximum temperature difference of $5^{\circ} \mathrm{C}$ in the operating area between TC2 and TC3 $(10 \mathrm{~mm}$ in length and $6 \mathrm{~mm}$ in diameter) and maximum cooling rates of $20^{\circ} \mathrm{C} / \mathrm{s}$ without additional air cooling. The cooling rate used by Archambault and Godard $\left(50^{\circ} \mathrm{C} / \mathrm{s}\right)$ was achieved by air cooling but led to a high overshoot in temperature stabilising after several seconds only and hence was not used.

Specimens were held horizontally by copper grips mounted on free jaws that can slide horizontally so that specimens are free to dilate. This assembly called "low force" is proposed by $\mathrm{DSI}^{\circledR}$ to measure accurately low forces at elevated temperatures. It was chosen to get rid of any mechanical issue such as buckling of the specimen. All measurements were performed under secondary vacuum (ca. $\left.10^{-1} \mathrm{~Pa}\right)$ to avoid oxidation of the copper wires.

\section{Results and discussion}

Pure aluminium. Preliminary IQ measurements were performed on $99.99 \%$ pure aluminium (A14N) specimens. The resistance decrease obtained by subtracting the resistance value at $530^{\circ} \mathrm{C}$ from the current resistance value is shown in Fig. 2 - left. 

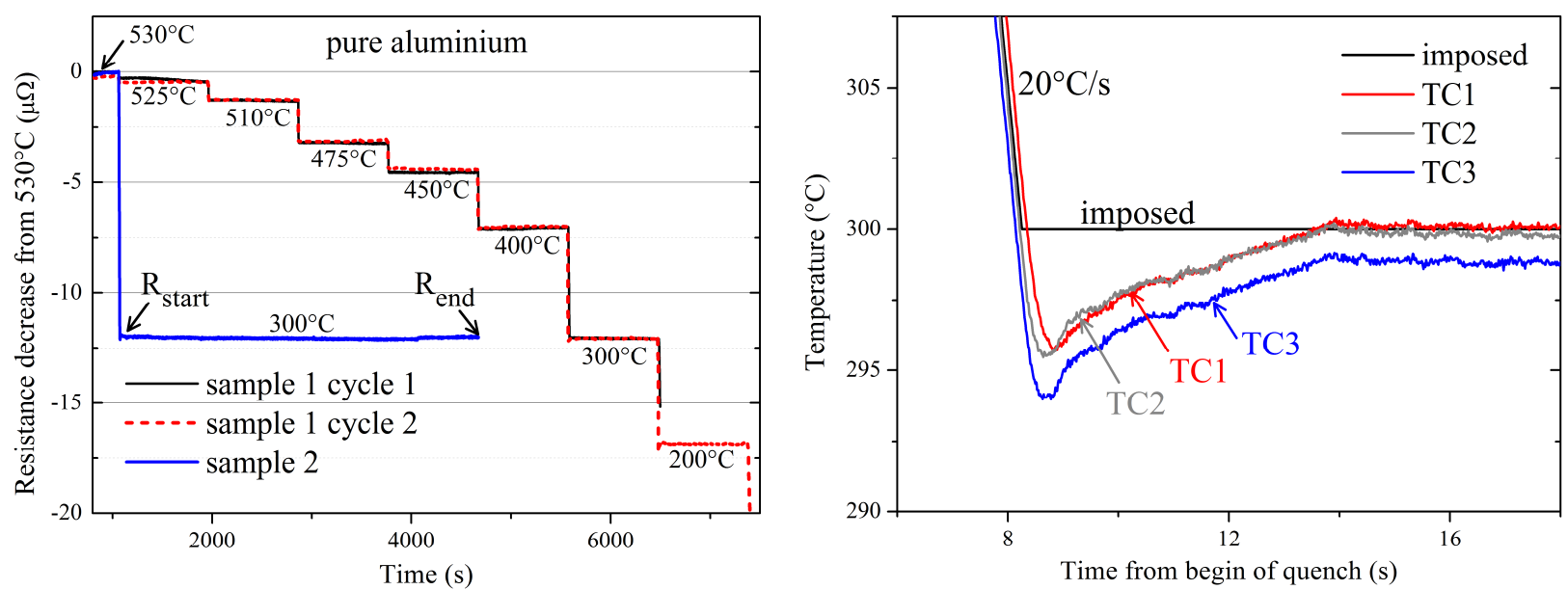

Figure 2: Evolution of resistance decrease from $530^{\circ} \mathrm{C}$ in pure aluminium specimens subjected to IQ at different temperatures (left) and example of measured temperatures in sample 2 (right).

One specimen was subjected to a first cycle (sample 1, cycle 1) consisting in a series of $15 \mathrm{~min}$ isothermal holdings at different temperatures. The same specimen underwent the same cycle (sample 1, cycle 2) for reproducibility purpose. Another specimen (sample 2) underwent an isothermal quenching at $300^{\circ} \mathrm{C}$ for 2 hours. Fig. 2 - right shows that cooling at $20^{\circ} \mathrm{C} / \mathrm{s}$ leads to a slight temperature undershoot $\left(5^{\circ} \mathrm{C}\right)$ and that temperature in the operating area is almost uniform.

As expected for pure aluminium, resistance is fairly constant on isothermals since no metallurgical change occurs. The slight drift of the resistance measured on isothermals is a measure of the relative error $\left(R_{\text {start }}-R_{\text {end }}\right) / R_{\text {start }}$, in the order of $1 \%$, where $R_{\text {start }}$ and $R_{\text {end }}$ are the values of the resistance decrease at the begin and at the end of the isothermal holding respectively.

Al-Zn-Cu-Mg based 7010 alloy. The results of IQ measurements performed on AA7010 are given in Fig. 3.

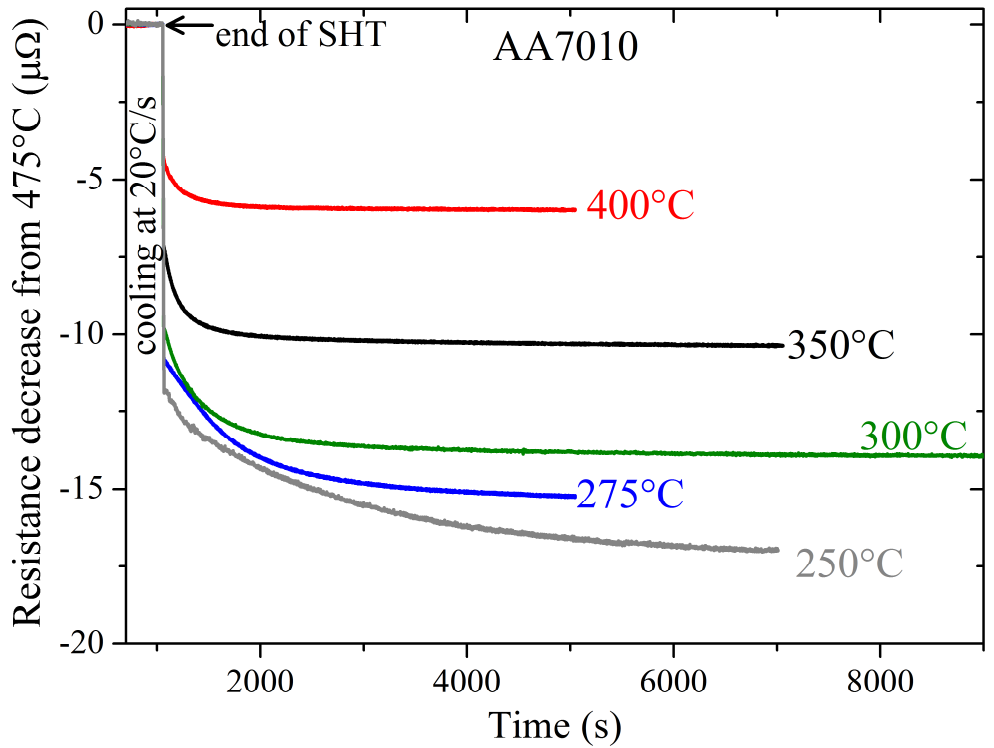

Figure 3: Evolution of resistance decrease from the SHT temperature in AA7010 specimens subjected to IQ at $20^{\circ} \mathrm{C} / \mathrm{s}$.

Unlike pure aluminium, AA7010 undergoes precipitation, as can be seen by the decrease of resistance on isothermals due to solute loss at temperatures ranging from $250^{\circ} \mathrm{C}$ to $400^{\circ} \mathrm{C}$. A convenient way to compare results is to calculate the relative resistance decrease $\rho$, defined as:

$$
\rho(T, t)=\frac{R(T, t)-R_{\text {start }}(T)}{R_{\text {end }}(T)-R_{\text {start }}(T)}
$$


Now $R_{\text {start }}$ is the value of the resistance decrease of the supersaturated SS and $R_{\text {end }}$ is the value of the resistance decrease after complete solute depletion of the matrix. The evolution of the relative resistance decrease of AA7010 is shown in Fig. 4 together with the results of Godard et al. on the same alloy [7].

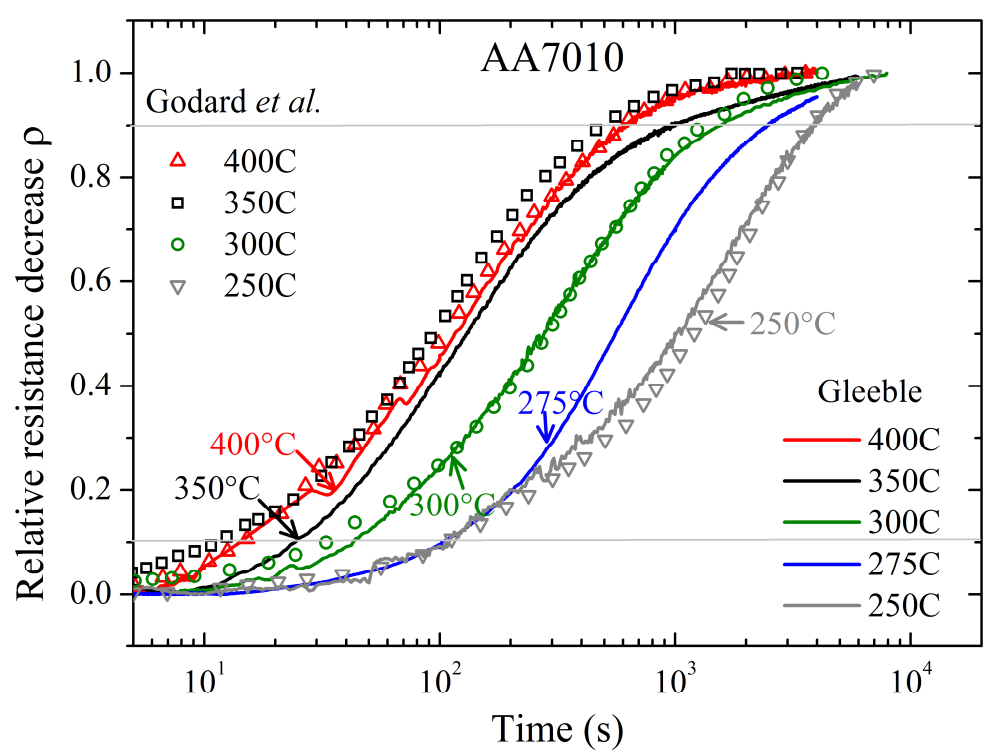

Figure 4: Normalised precipitation kinetics of AA7010: comparison between Gleeble's results and literature.

The difference between our results and the literature is maximum at $350^{\circ} \mathrm{C}$ where Godard et al. measured the fastest kinetics, which is observed at $400^{\circ} \mathrm{C}$ in the Gleeble machine. The difference of relative resistance decrease at $350^{\circ} \mathrm{C}$ (ca. $10 \%$ of the measured value) is acceptable considering the different chemical composition of the two AA7010 alloys. The difference between our results and the literature at 250,300 and $400^{\circ} \mathrm{C}$ is to be expected $(<5 \%)$ considering the different (1) cooling rates, (2) temperature profiles in the specimens and (3) techniques of resistance measurement. The overall good agreement between our results and the literature proves that the Gleeble machine is a valuable alternative to home-made quench resistivimeters.

\section{Conclusion}

Solute loss can be monitored by resistivity measurement with a Gleeble machine. The measured precipitation kinetics of $\mathrm{Al}-\mathrm{Zn}-\mathrm{Cu}-\mathrm{Mg}$ based 7010 alloy is in good agreement with the results of Godard et al. on the same alloy using a home-made quench resistivimeter. The present validation of isothermal quenching resistivity measurement in a Gleeble machine is the basis for future characterisation of precipitation kinetics in less quench sensitive heat treatable aluminium alloys with critical cooling rates lower than $20^{\circ} \mathrm{C} / \mathrm{s}$.

\section{Acknowledgements}

This work is funded by the Competence Center for Materials Science and Technology (http://www.ccmx.ch/) in the frame of the project entitled "Measurements and modelling of residual stress during quenching of thick heat treatable aluminium components in relation to their microstructure" involving EPF Lausanne, PSI Villigen, Univ. de Bretagne Sud Lorient, Constellium CRV and ABB Turbosystems AG. The Gleeble 3500 machine of Université de Bretagne Sud was co-financed by European Regional Development Fund (ERDF). The authors are grateful to E. AebyGautier (Univ. Lorraine) for fruitful discussion, J. Costa (Univ. Bretagne Sud) for the instrumentation and M. Carin (Univ. Bretagne Sud) for the thermo-electrical models of the Gleeble specimens. 


\section{References}

[1] M. Perez, O. Lame and A. Deschamps, Global techniques for characterizing phase transformations: a tutorial review, Adv. eng. Mat., 12 (2010) 433-446

[2] S. I. Vooijs, S. B. Davenport and I. Todd, Monitoring the precipitation reactions in a cold-rolled $\mathrm{Al}-\mathrm{Mn}-\mathrm{Mg}-\mathrm{Cu}$ alloy using thermoelectric power and electrical resistivity measurements, Philosophical Magazine A, 81,8 (2001) 2059-2072

[3] M. Dehmas, P. Weisbecker, G. Geandier, P. Archambault and E. Aeby-Gautier, Experimental study of phase transformations in 3003 aluminium alloys during heating by in situ high energy Xray synchrotron radiation, Journal of Alloys and Compounds, 400 (2005) 116-124

[4] P. Archambault and D. Godard, High temperature precipitation kinetics and TTT curve of a $7 \mathrm{xxx}$ alloy by in-situ electrical resistivity measurements and differential calorimetry, Scripta Materialia, 42 (2000) 675-680

[5] R.H. Brown and L.A. Willey, Aluminium Vol I: Properties, Physical Metallurgy, and Phase. Diagrams, K.R. Van Horn, ed., ASM, Metals Park, OH, 1967

[6] C. Samuel and S. Viswanathan, Specimen configurations for Gleeble dilatometry of steels, Materials Science \& Technology, ASM, Materials Park, OH (2008) 1872-1883

[7] D. Godard, E. Gautier, P. Archambault and C. Sigli, The modelling of the heterogeneous precipitation in Al-Zn-Mg-Cu alloys during quenching, Proceedings of the International Conference on Solid-Solid Phase Transformations, edited by M. Koiwa, K. Otsuka and T. Miyazaki, The Japan Institute of Metals (1999) 145-148 